Article

\title{
Bioactivation and Regioselectivity of Pig Cytochrome P450 3A29 towards Aflatoxin $B_{1}$
}

\author{
Jun $\mathrm{Wu}^{\dagger}{ }^{\text {, Ruohong Chen }}{ }^{\dagger}$, Caihui Zhang, Kangbai Li, Weiying Xu, Lijuan Wang, Qingmei Chen, \\ Peiqiang Mu, Jun Jiang, Jikai Wen and Yiqun Deng * \\ Guangdong Provincial Key Laboratory of Protein Function and Regulation in Agricultural Organisms, \\ College of Life Sciences, South China Agricultural University, Guangzhou 510642, China; \\ wujun@scau.edu.cn (J.W.); Ruohongchen@hotmail.com (R.C.); zhangcaihui11@gmail.com (C.Z.); \\ kangboli@gmail.com (K.L.); grace87330@163.com (W.X.); wlj322@scau.edu.cn (L.W.); \\ chenqingmei@scau.edu.cn (Q.C.); mpeiqiang@scau.edu.cn (P.M.); jiangjun@scau.edu.cn (J.J.); \\ jkwen@scau.edu.cn (J.W.) \\ * Correspondence: yqdeng@scau.edu.cn; Tel.: +86-20-3860-4967 \\ + These authors contributed equally to this work. \\ Academic Editor: Shohei Sakuda \\ Received: 29 June 2016; Accepted: 5 September 2016; Published: 12 September 2016
}

\begin{abstract}
Due to unavoidable contaminations in feedstuff, pigs are easily exposed to aflatoxin $B_{1}$ $\left(\mathrm{AFB}_{1}\right)$ and suffer from poisoning, thus the poisoned products potentially affect human health. Heretofore, the metabolic process of $\mathrm{AFB}_{1}$ in pigs remains to be clarified, especially the principal cytochrome P450 oxidases responsible for its activation. In this study, we cloned CYP3A29 from pig liver and expressed it in Escherichia coli, and its activity has been confirmed with the typical P450 CO-reduced spectral characteristic and nifedipine-oxidizing activity. The reconstituted membrane incubation proved that the recombinant CYP3A29 was able to oxidize $\mathrm{AFB}_{1}$ to form $\mathrm{AFB}_{1}$-exo-8,9-epoxide in vitro. The structural basis for the regioselective epoxidation of $\mathrm{AFB}_{1}$ by CYP3A29 was further addressed. The T309A mutation significantly decreased the production of $\mathrm{AFBO}$, whereas $\mathrm{F} 304 \mathrm{~A}$ exhibited an enhanced activation towards $\mathrm{AFB}_{1}$. In agreement with the mutagenesis study, the molecular docking simulation suggested that Thr309 played a significant role in stabilization of $\mathrm{AFB}_{1}$ binding in the active center through a hydrogen bond. In addition, the bulk phenyl group of Phe304 potentially imposed steric hindrance on the binding of $\mathrm{AFB}_{1}$. Our study demonstrates the bioactivation of pig CYP3A29 towards $\mathrm{AFB}_{1}$ in vitro, and provides the insight for understanding regioselectivity of CYP3A29 to $\mathrm{AFB}_{1}$.
\end{abstract}

Keywords: cytochrome P450; CYP3A29; $\mathrm{AFB}_{1}$; bioactivation; regioselectivity

\section{Introduction}

Aflatoxins are secondary metabolites mainly produced by Aspergillus flavus and Aspergilus parasiticus [1]. They are highly toxic and carcinogenic to animals and humans. Aflatoxin infection is believed to induce hepatocellular carcinoma [2]. Aflatoxin $\mathrm{B}_{1}\left(\mathrm{AFB}_{1}\right)$ is the most toxic and widely distributed of all identified aflatoxins [3,4]. $\mathrm{AFB}_{1}$ is not toxic in its native form, but highly activated when converted to electrophilic $\mathrm{AFB}_{1}$ exo-8,9-epoxide (AFBO) in vivo [5,6]. AFBO is highly reactive and easily intercalates into DNA, resulting in the genotoxicity of $\mathrm{AFB}_{1}$ [7]. Extensive research has confirmed that CYP3A4 and CYP1A2 play central roles in the bioactivation of $\mathrm{AFB}_{1}$ in human [8-10], though there remain some controversies about their relative dominance during this process [10-13]. Compared to CYP3A4, CYP1A2 is believed to have a higher affinity to $\mathrm{AFB}_{1}$ and to activate the carcinogen at relative lower substrate concentrations [11,12]. However, some researchers still think CYP3A4 plays a more important role in $\mathrm{AFB}_{1}$ activation based on the following experimental facts: (i) CYP3A4 is far more abundant than CYP1A2 in the human liver [14]; (ii) CYP3A4 transforms $\mathrm{AFB}_{1}$ 
into exo-8,9-epoxide and a detoxification product $\mathrm{AFQ}_{1}$ [15]; and (iii) CYP1A2 metabolizes $\mathrm{AFB}_{1}$ into detoxification product $\mathrm{AFM}_{1}$, exo- and endo-8,9-epoxides [15], in which endo-8,9-epoxide is not biologically active $[16,17]$. As the most abundant CYP in the human liver and also the major enzyme responsible for the metabolism of many exogenous and endogenous compounds, CYP3A4 has been studied extensively [18-21]. Some CYP3A4 orthologs in other species or tissues have been identified and proved to play the same important roles as human CYP3A4 in $\mathrm{AFB}_{1}$ activation. For instance, CYP3A37 in the turkey liver [22], CYP3A6 in the rabbit liver [23] and CYP3A enzymes in the human lung [24] have been shown to be enzymes that activate $\mathrm{AFB}_{1}$ into $\mathrm{AFBO}$. Besides CYP1A2 and CYP3A4, it has been reported that human CYP2A6, CYP2A13, and CYP2B7 are also active in converting $\mathrm{AFB}_{1}$ to active metabolites $[8,9,25-27]$, which shows that humans have a large capacity to activate the toxin. Because of the low content in the liver [28], it is unlikely that CYP2A6 and CYP2B6 have a major contribution to $\mathrm{AFB}_{1}$ activation in vivo. CYP3A5 is another important human CYP3A isoform, which shares $85 \%$ amino acid sequence identity with CYP3A4 [29] and account for approximately $30 \%-40 \%$ of the total hepatic 3A [30]. Different to CYP1A2 and CYP3A4, CYP3A5 largely transforms AFB 1 into AFBO [29,31], while its transformation rate is notably lower than the others [11,29].

Pigs are indispensable domestic animals in stockbreeding, and their products have a long successful history of providing tremendous contributions to human nutrition and health. In addition, although rodents are the species generally used for metabolic and pharmacological studies, pigs could provide closer reflections of the metabolic mechanism of drugs and other xenobiotics, and consequently have been attracting increasing attention [32]. As one of the domestic animals that are most raised and consumed in China, pigs are easily exposed to $\mathrm{AFB}_{1}$ and suffer from poisoning due to aflatoxin-contaminated feedstuff [33]. However, the metabolic pathway of $\mathrm{AFB}_{1}$ in pigs, especially the principal $\mathrm{P} 450$ oxidases responsible for the activation of $\mathrm{AFB}_{1}$, has yet to be addressed in research.

CYP3A29 is one of the pig CYP3A isoforms, and it has been reported to have a major impact in total CYP3A activity in pig liver microsomes [34]. Specifically, pig CYP3A29 has been shown to have similarity to human CYP3A4 in tissue distribution, testosterone oxidation kinetics, and ketoconazole inhibitory kinetics [34].

In this study, we demonstrated that the recombinant CYP3A29 expressed in E. coli was capable of transforming $\mathrm{AFB}_{1}$ into $\mathrm{AFBO}$. According to molecular docking prediction and the related study reports [35,36], we selected Ser119, Phe304, and Thr309 as potentially important residues that may be involved in the interaction of CYP3A29 with $\mathrm{AFB}_{1}$. To gain further insights into the regioselectivity of CYP3A29 towards $\mathrm{AFB}_{1}$, we purified S119A, F304A, and T309A mutants and compared their activities in $\mathrm{AFB}_{1}$ epoxidation. Based on the results of mutant activity, further molecular docking showed that Thr309 played a key role by forming a hydrogen bond with $\mathrm{AFB}_{1}$; Phe304 caused steric hindrance to $\mathrm{AFB}_{1}$ and Ser119 contributed to polar interaction. To our best knowledge, this is the first report about pig CYP that is involved in the metabolic activation of $\mathrm{AFB}_{1}$, and this work exhibits the difference of regioselectivity of $\mathrm{AFB}_{1}$ epoxidation between CYP3A29 and CYP3A4.

\section{Results}

\subsection{Activation of $A F B_{1}$ by $C Y P 3 A 29$}

The recombinant pig CYP3A29 and its mutants were cloned and expressed as His $_{6}$-tagged fusion protein in Escherichia coli. CYP3A29 WT with an apparent molecular mass of $60 \mathrm{kDa}$ was obtained by affinity chromatography, and its purity exceeded $95 \%$ (Figure 1A, lane 4). The production of protein was estimated to be approximately $20.8 \mathrm{mg} / \mathrm{L}$ bacterial culture. $\mathrm{Fe}^{2+} \cdot \mathrm{CO}$ vs. $\mathrm{Fe}^{2+}$ difference spectra of CYP3A29 and the mutants are shown in Figure 1B. The recombinant proteins had a strong absorbance around $450 \mathrm{~nm}$ and no absorbance peak at $420 \mathrm{~nm}$, indicating that CYP3A29 WT and the mutants expressed in the E. coli membrane possessed the spectral characteristics of functional P450.

To assess whether the recombinant CYP3A29 had epoxidation activity towards $\mathrm{AFB}_{1}$, incubation of $\mathrm{CYP}_{3} \mathrm{~A} 29$ with $\mathrm{AFB}_{1}$ was performed. Because of the strong activation towards $\mathrm{AFB}_{1}$, quail liver 
microsomes were used as a positive control to identify the $\mathrm{AFB}_{1}$ metabolites produced by CYP3A29 [37,38]. As shown in Figure $1 \mathrm{C}$ top, a major product peak appeared at $t_{\mathrm{R}} 12.2 \mathrm{~min}$ after $\mathrm{AFB}_{1}$ incubation with quail liver microsomes. It has been reported that almost all $\mathrm{AFB}_{1}$ are metabolized to $\mathrm{AFBO}$ by quail liver microsomes, which can be assessed by the formation of dihydrodiol-Tris [39]. Meanwhile, the product peak at $t_{\mathrm{R}} 12.2 \mathrm{~min}$ disappeared in the absence of Tris in a control experiment (data not shown). Using LC-MS/MS (Agilent 6410B Triple Quad system, Santa Clara, CA, USA, Figure S1), we further identified that the metabolite at $t_{\mathrm{R}} 12.2 \mathrm{~min}$ was a dihydrodiol-Tris conjugate (see the structure in Figure 1C). When CYP3A29 was incubated with AFB $_{1}$, an identical peak was detected at $t_{\mathrm{R}} 12.2 \mathrm{~min}$ (Figure 1C, middle). Furthermore, in the presence of $5 \mu \mathrm{M}$ ketoconazole, the product at $t_{\mathrm{R}} 12.2$ min was lost (Figure 1C, bottom), indicating that the oxidizing activity of CYP3A29 to AFB 1 was efficiently inhibited by the specific CYP3A inhibitor. These results indicated that recombinant pig CYP3A29 expressed in E. coli possessed substantial AFB 1 oxidizing activity and was indeed capable of activating $\mathrm{AFB}_{1}$ in vitro.

A

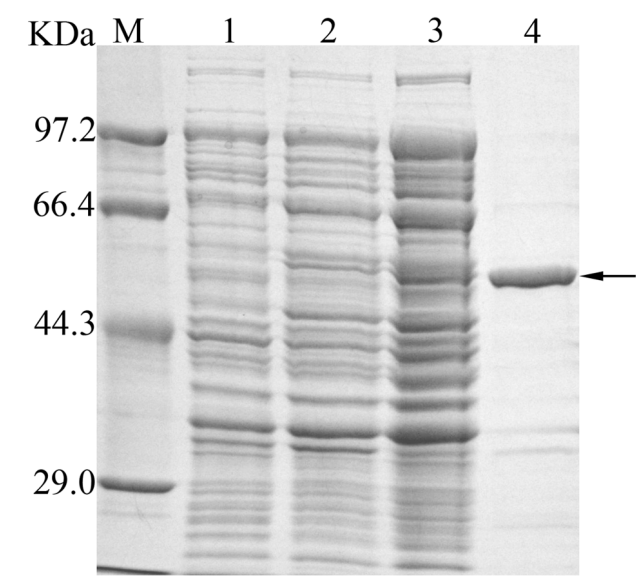

B

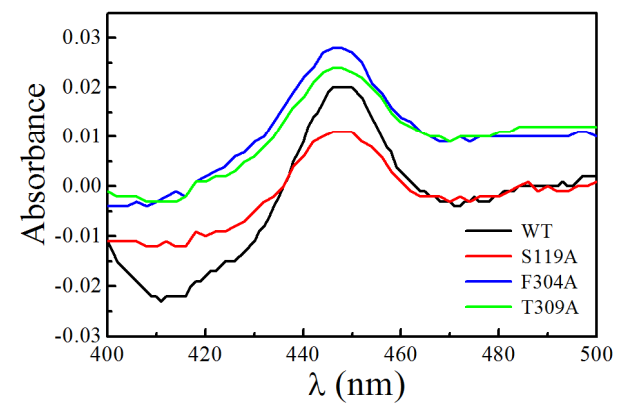

C

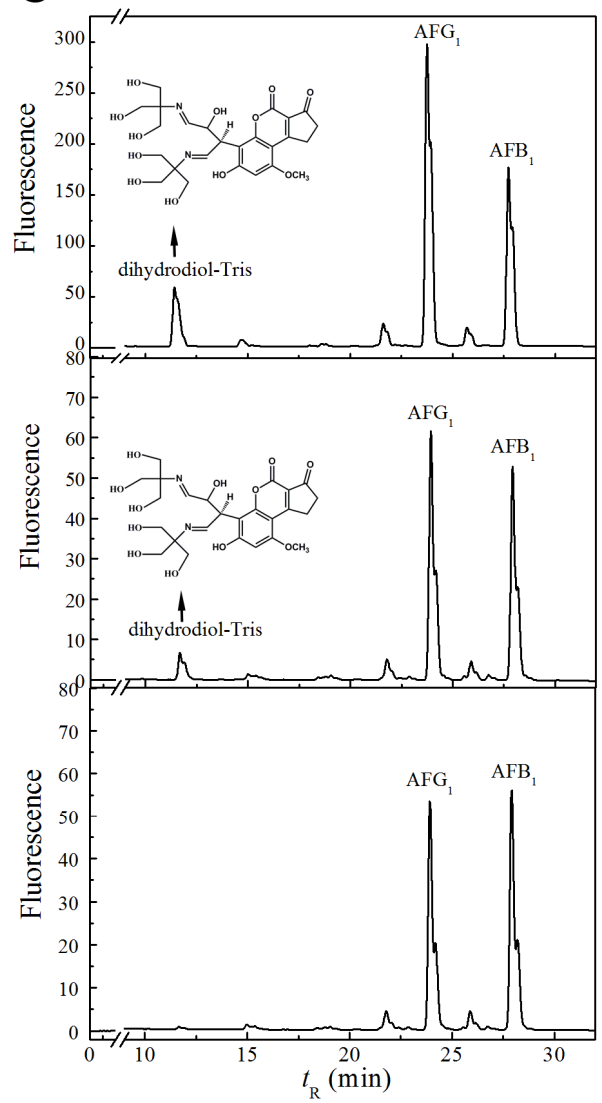

Figure 1. Purification, $\mathrm{CO}$ difference spectra, and $\mathrm{AFB}_{1}$ oxidation activity of recombinant pig CYP3A29. (A) Expression and purification of CYP3A29 in E. coli DH5 $\alpha$. The band around $60 \mathrm{kDa}$ is the protein of interest (arrow). M: protein marker; Lane 1: non-IPTG induced total cell lysates; Lane 2: IPTG-induced total cell lysates; Lane 3: the solubilized membrane components; Lane 4: purified recombinant pig CYP3A29. (B) $\mathrm{Fe}^{2+} \cdot \mathrm{CO}$ vs. $\mathrm{Fe}^{2+}$ difference spectra of CYP3A29 and the mutants. The spectra were recorded at $25^{\circ} \mathrm{C}$ and in $100 \mathrm{mM}$ Tris. $\mathrm{HCl}$ buffer ( $\mathrm{pH}$ 7.4) containing $10 \mathrm{mM} \mathrm{CHAPS,} \mathrm{20 \%} \mathrm{glycerol,}$ and 1 mM EDTA. (C) Top: the HPLC chromatogram of $\mathrm{AFB}_{1}$ metabolized by quail liver microsomes; Middle: HPLC chromatogram of $\mathrm{AFB}_{1}$ metabolized by recombinant CYP3A29; Bottom: CYP3A29 was inhibited by $5 \mu \mathrm{M}$ ketoconazole and no metabolite formed. The dihydrotriol-tris is an indirect indication of the formation of the major metabolite $\mathrm{AFBO}$ and $\mathrm{AFG}_{1}$ was added into the reaction mixture as an internal standard. HPLC eluent was monitored by fluorescence $\left(\lambda_{\text {excitation }}=365 \mathrm{~nm}\right.$, $\left.\lambda_{\text {emission }}=440 \mathrm{~nm}\right)$. 


\subsection{The CD Spectra and Nifedipine-Oxidized Activities of CYP3A29 and Its Mutants}

To obtain information about the secondary structure of CYP3A29 and its mutants, we carried out circular dichroism experiments. The far-UV CD spectra of all the proteins displayed two negative peaks at $208 \mathrm{~nm}$ and $222 \mathrm{~nm}$ (Figure 2A), suggesting typical structures rich in $\alpha$-helixes. The analysis by CONTINLL software (Colorado State University, Fort Collins, CO, USA, 2000) showed that the recombinant CYP3A29 contained $48.7 \% \alpha$-helix and $9 \% \beta$-sheet (Table 1), which is similar to the contents of the secondary structure of human CYP3A4 (43\% $\alpha$-helix and 7\% $\beta$-sheet, data from RCSB Protein Data Bank, 1WOE). The secondary structure contents (45.7\% $\alpha$-helix and $11 \% \beta$-sheet, Table 1) of S119A were approximately the same as those of WT. Interestingly, compared with the other proteins, F304A contained the minimum $\alpha$-helix (40.7\%) and maximum $\beta$-sheet $(13.9 \%)$, which was exactly the opposite to the case of T309A ( $52.8 \% \alpha$-helix, $7.9 \% \beta$-sheet, Table 1$)$.
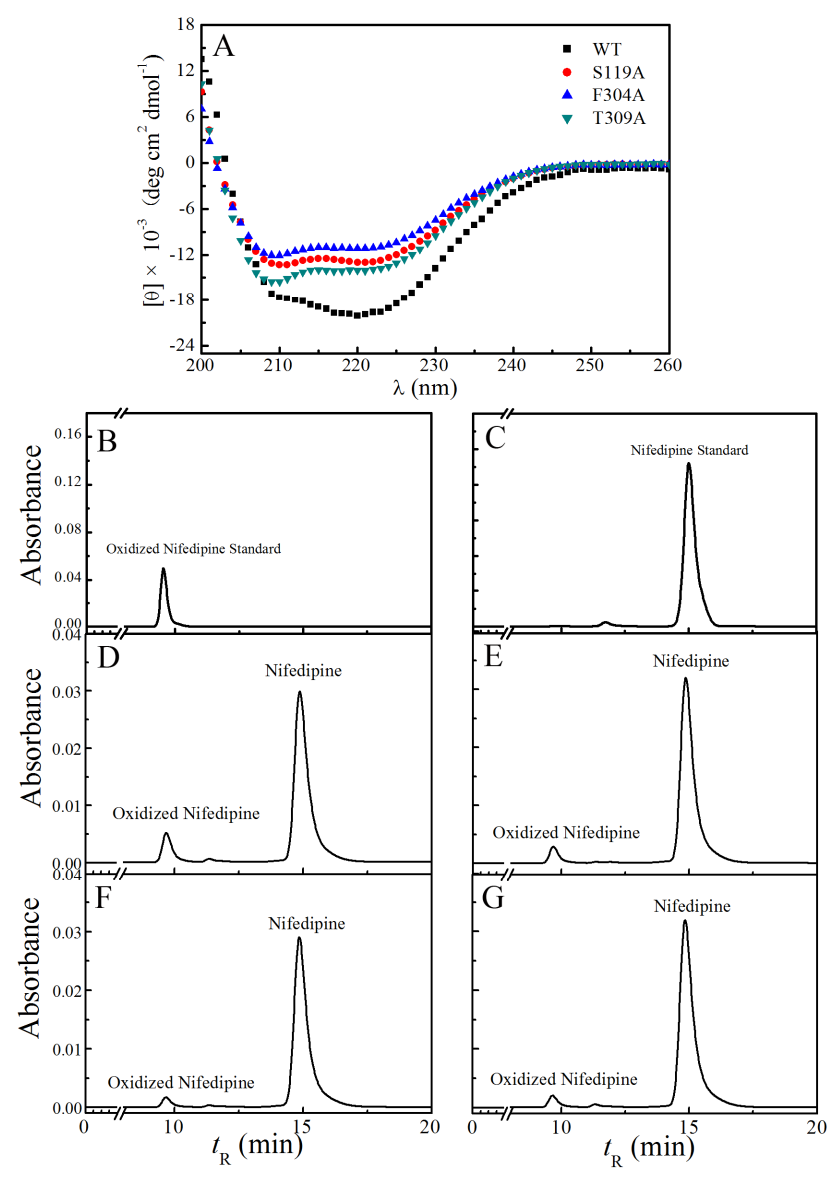

Figure 2. The circular dichroism spectra and CYP3A29 and the mutants' nifedipine oxidation activities. (A) Far-UV CD spectra of CYP3A29 and its mutants. CD spectra were recorded at $20{ }^{\circ} \mathrm{C}$ and in $50 \mathrm{mM}$ potassium phosphate buffer $(200 \mathrm{mM} \mathrm{KCl}, 0.2 \mathrm{mM} \mathrm{DTT}, 1 \mathrm{mM}$ EDTA, and 20\% glycerol, $\mathrm{pH}$ 7.4). (B-G) The HPLC chromatogram of oxidized nifedipine standard; the HPLC chromatogram of nifedipine standard; HPLC chromatograms of nifedipine metabolized by WT, S119A, F304A, and T309A, respectively. HPLC eluent was monitored by absorbance at $254 \mathrm{~nm}$.

Nifedipine was used as the specific substrate for CYP3A family to assess the activities of CYP3A29 and the mutants. The HPLC results displayed that nifedipine could be metabolized into oxidized nifedipine by all the enzymes after in vitro incubations, as confirmed by the product standard (Figure 2B). Native CYP3A29 exhibited the maximum oxidizing activity to nifedipine (Figure 2D), whereas S119A had only a half activity of the WT towards the model substrate (Figure 2E). F304A and T309A showed even weaker oxidation than S119A (Figure 2F,G). These results reflected the effect of specific residue on recognizing nifedipine. 
Table 1. Contents of secondary structure elements of CYP3A29 and its mutants. CD spectra were analyzed by CONTINLL with a 56-protein Reference [40].

\begin{tabular}{|c|c|c|c|c|}
\hline Samples & $\alpha$-Helix & $\beta$-Sheet & Turns & Unordered \\
\hline- & - & \multicolumn{2}{|c|}{$\%$} & - \\
\hline WT & 48.7 & 9 & 16.2 & 26.1 \\
\hline S119A & 45.7 & 11 & 17.7 & 25.5 \\
\hline F304A & 40.7 & 13.9 & 18.4 & 27 \\
\hline T309A & 52.8 & 7.9 & 14.9 & 24.3 \\
\hline
\end{tabular}

\subsection{Comparison of $A F B_{1}$ Activation by CYP3A29 and Its Mutants}

To explore the regioselectivity and specificity of pig CYP3A29 towards $\mathrm{AFB}_{1}$, we carried out the incubation of CYP3A29 and its mutants with $\mathrm{AFB}_{1}$. Oxidizing activities of all recombinant enzymes towards $\mathrm{AFB}_{1}$ can be relatively quantified and compared by analyzing the ratio of peak area of the main product to that of $\mathrm{AFG}_{1}$ (the original data was shown in Table S1). The relative activities of WT and its mutants can be seen in Figure 3E. Compared with WT (Figure 3A), the substitution of Ser119 with Ala resulted in the middle impairment (about 50\%) of $\mathrm{AFB}_{1}$ exo-epoxidation (Figure 3B). Unexpectedly, replacement of Phe304 with Ala led to over 2-fold increase of $\mathrm{AFB}_{1}$ epoxidation activity (Figure 3C), which is totally opposite to the result observed in human CYP3A4 [36]. For Thr309, its substitution with Ala resulted in the significant impairment (about $80 \%$ ) of $\mathrm{AFB}_{1}$ exo-epoxidation (Figure 3D), which implied that threonine at the position 309 may play an important role in the activation of $\mathrm{AFB}_{1}$.
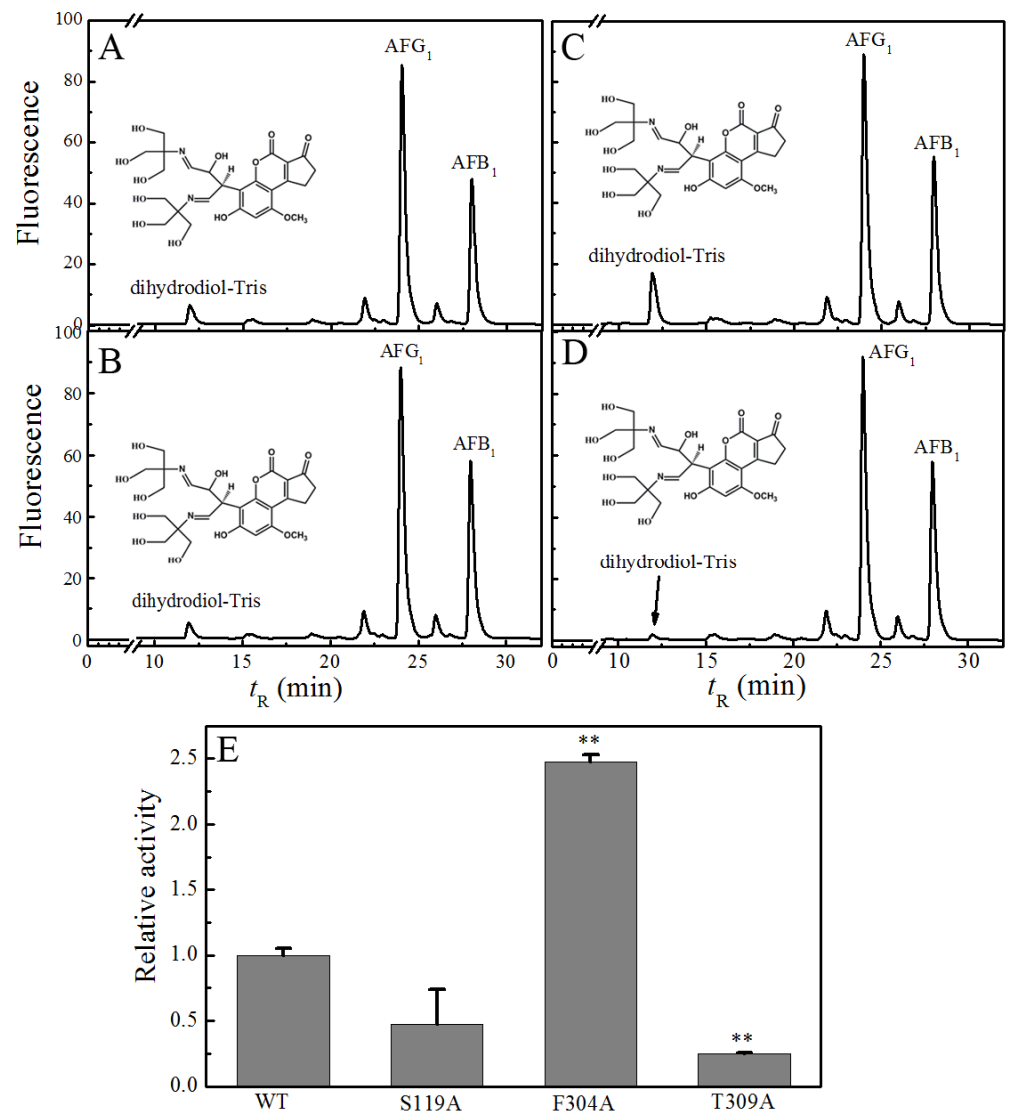

Figure 3. $\mathrm{AFB}_{1}$ oxidation by CYP3A29 and the mutants. (A-D) HPLC chromatograms of $\mathrm{AFB}_{1}$ metabolized by WT, S119A, F304A, and T309A, respectively; (E) histograms of relative activities of CYP3A29 and the mutants towards $\mathrm{AFB}_{1}$. The dihydrotriol-tris is an indirect indication of the formation of the major metabolite $\mathrm{AFBO}$ and $\mathrm{AFG}_{1}$ was added as an internal standard. HPLC eluent was monitored by fluorescence $\left(\lambda_{\text {excitation }}=365 \mathrm{~nm}, \lambda_{\text {emission }}=440 \mathrm{~nm}\right) .{ }^{* *} p<0.01$, Values are means $\pm \operatorname{SE}(n=3)$. 


\subsection{Molecular Docking of $A F B_{1}$ into CYP3A29 and the Mutants}

CYP3A29 structure generated by SWISS-MODEL server was firstly evaluated by PROCHECK program, which gives a Ramachandran plot and a quantitative distribution of residues [41]. The percentage of residues in the most favored, allowed, and disallowed conformations were $78.1 \%$, $21.4 \%$, and $0.5 \%$, respectively. The overall quality factor calculated by Errat was 74 . And the averaged 3D-1D score passed the verification by Verify_3D.

To establish a binding model and understand the details of interaction between ligand and receptor, we carried out the molecular docking study on $\mathrm{AFB}_{1}$ with CYP3A29 and its mutants. One hundred docking conformations generated by AutoDock 4.2 were clusters with an RMSD of $2.0 \AA$ and ranked by the lowest docked energy. Two clusters were produced by the docking simulations when $\mathrm{AFB}_{1}$ was docked into receptor CYP3A29 WT, F304A, and S119A respectively, and only one for T309A. For WT, the first cluster contained $37 \%$ conformers and had $-8.58 \mathrm{kcal} / \mathrm{mol}$ of the lowest binding energy (Table 2). It can be seen from the side view of the docking model that $\mathrm{AFB}_{1}$ was located to the upper right of the heme iron (Figure S2), in which orientation the epoxy bond could form only on the left of the terminal furan ring. Stereochemically, this is $\mathrm{AFB}_{1}$-exo-8,9-epoxide. Consistent with the previous reports [31,36], the docking only produced the orientation that was favorable for forming exo-8,9-epoxidation while no orientation for endo-8,9-epoxidation. In the first cluster, $\mathrm{AFB}_{1}$ almost stood vertically onto the heme, the redox center, with its $\mathrm{C} 8$ oriented towards the heme iron (Figure 4A). Furthermore, the measured interatomic distance between $\mathrm{C} 8$ and heme iron was $2.7 \AA$ (Figure 4A), which allowed the contact of the ferric peroxy anion and led to the electrons' transfer from the substrate and the subsequent formation of AFBO. Therefore, the conformations in this cluster predicted formation of active metabolite. For the other cluster, on the contrary, the docking result showed that the oxygen atom at $\mathrm{C} 1$ of $\mathrm{AFB}_{1}$ was oriented towards the heme iron, whereas $\mathrm{C} 8$, C9-double bond was far away from the oxidized center, in which case no AFBO could be formed, thus these conformations were thought inactive. It also can be seen from the putative binding model that $\mathrm{AFB}_{1}$ interacted with residues in the active site by forming two hydrogen bonds: one was between side chain hydroxyl group of Tyr309 and $\mathrm{O} 6$ or $\mathrm{O} 7 \mathrm{of} \mathrm{AFB}_{1}$; the other was between the oxygen atom at $\mathrm{C} 4$ of $\mathrm{AFB}_{1}$ and the hydrogen in a peptide bond formed by Lys212 with Phe213 (Figure 4A). It is speculated that these two hydrogen bonds ought to play special roles in maintaining the stable binding of $\mathrm{AFB}_{1}$ in the active center.

When Phe304 was substituted with Ala, the orientational transformation of $\mathrm{AFB}_{1}$ molecule could be observed through the docking simulation. $87 \%$ conformers were organized into the first cluster, with $-8.74 \mathrm{kcal} / \mathrm{mol}$ of the lowest binding energy (Table 2). Similar to the pose in WT, $\mathrm{C} 8$ of $\mathrm{AFB}_{1}$ was still directed towards the heme iron, with a interatomic distance of $3.1 \AA$ (Figure $4 \mathrm{~B}$ ). However, $\mathrm{AFB}_{1}$ in F304A rotated clockwise for $42.1^{\circ}$ compared with the pose in WT, turning into nearly parallel to I helix on the right side (Figure 4B). In this conformation, a new hydrogen bond was formed between the side chain hydroxyl group of Ser119 and carbonyl group oxygen at $\mathrm{C} 1$ or $\mathrm{C} 11$ of $\mathrm{AFB}_{1}$ (Figure $4 \mathrm{~B}$ ), which would further stabilize the binding of $\mathrm{AFB}_{1}$ in the active center.

Table 2. Conformation distributions and the lowest binding energy of $\mathrm{AFB}_{1}$ docked into CYP3A29 and its mutants.

\begin{tabular}{cccc}
\hline Protein & Active $^{*}$ & Inactive & Lowest Binding Energy \\
** (kcal/mol) \\
\hline WT & $37 \%$ & $63 \%$ & -8.55 \\
S119A & $40 \%$ & $60 \%$ & -8.57 \\
F304A & $87 \%$ & $13 \%$ & -8.74 \\
T309A & 0 & $100 \%$ & - \\
\hline
\end{tabular}

* Percentages were obtained by calculating the ratio of active or inactive conformation quantity to 100 conformations;

** Only point to the energy in active conformation. 


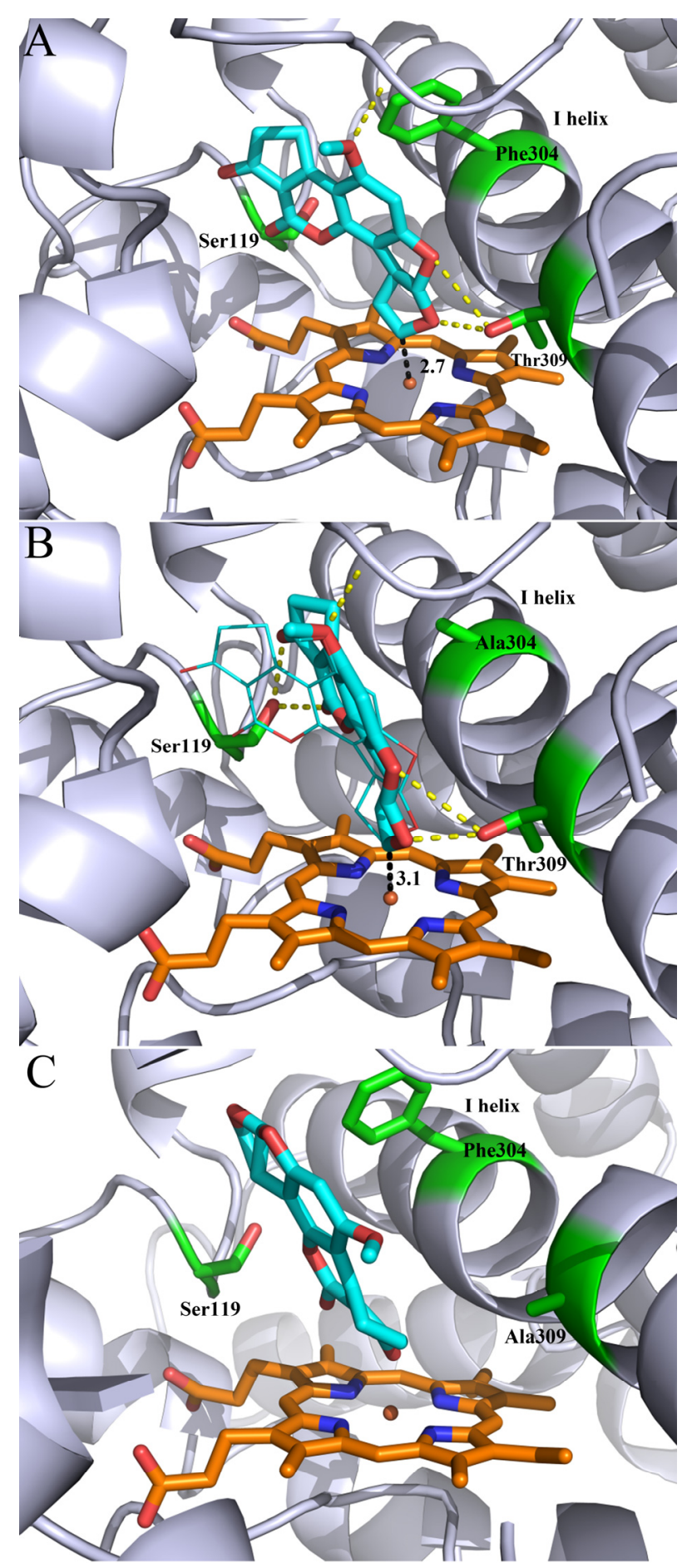

Figure 4. Molecular models of $\mathrm{AFB}_{1}$ docked into CYP3A29 and the mutants. (A) The docking conformation of $\mathrm{AFB}_{1}$ in the active site of CYP3A29; (B) the docking conformation of $\mathrm{AFB}_{1}$ in $\mathrm{F}_{304 \mathrm{~A}}$. The best conformation of $\mathrm{AFB}_{1}$ was docked into $\mathrm{F} 304 \mathrm{~A}$ (shown as thick sticks), while that of $\mathrm{AFB}_{1}$ in WT is shown as thin sticks; $(C)$ The docking conformation of $\mathrm{AFB}_{1}$ in T309A. CYP3A29 is shown in a ribbon format, and an iron ion is shown as a sphere. The examined amino acid residues are green, and the heme is orange. Color scheme: red for oxygen atoms and blue for nitrogen atoms. Hydrogen bonds are shown as yellow dashed lines, and distances between atoms are shown with black dashed lines and given in angstroms. Residues 368-371 and 476-484 are not shown, for clarity. The figures are rendered with PyMOL (Version 1.8, Schrodinger, LLC., New York, NY, USA, 2015) [42]. 
For the replacement of Thr309 with Ala, interestingly, only one cluster was produced by the docking simulation. In all conformations within the cluster oxygen atom at $\mathrm{AFB}_{1} \mathrm{C} 1$ was directed towards the heme iron (Figure $4 \mathrm{C}$ ), suggesting no plausible oxidation product (Table 2). This result revealed that Thr309 may play a critical role in keeping the correct orientation of $\mathrm{AFB}_{1}$ because the loss of the hydrogen bond between aflatoxin and the amino acid resulted in the molecular inversion of $\mathrm{AFB}_{1}$ and formation of the inactive pose.

Considering that S119A mutation did not result in obvious alteration on both active conformation proportion $(40 \%)$ and the lowest binding energy $(-8.57 \mathrm{kcal} / \mathrm{mol}$, Table 2$)$ in comparison with the WT according to the docking results, it is unlikely that Ser119 is involved in direct interaction with $\mathrm{AFB}_{1}$.

\section{Discussion}

The key $\mathrm{P} 450$ oxidases responsible for the bioactivation of $\mathrm{AFB}_{1}$ in numbers of species or tissues have been well documented [22-24,43]. In pigs, four CYP3A isoforms, CYP3A22, CYP3A29, CYP3A39, and CYP3A46, have been identified so far, and characterized mainly in T-2 biotransformation $[34,44-46]$. The oxidation of testosterone and nifedipine by pig CYP3A29 has been well characterized [34]. However, there are no data on $\mathrm{P} 450$-mediated activation of $\mathrm{AFB}_{1}$ in pigs. In this study we focused on the cloning and characterization of CYP3A29, and investigation of the interaction of this enzyme with $\mathrm{AFB}_{1}$, demonstrating that CYP3A29 mediated conversion of aflatoxin to the toxic epoxide.

The recombinant CYP3A29 expressed in E. coli demonstrated a typical P450 spectral characteristic. The ordered secondary structure was confirmed by CD spectra. In the in vitro incubation experiment, to validate the activity of $\mathrm{P} 450$ oxidase, nifedipine, the CYP3A4 specific substrate was transformed into the oxidized form by purified CYP3A29, suggesting that the expressed recombinant enzyme has the capacity for biotransformation of compounds. In vitro incubation experiments further confirmed that CYP3A29 converts $\mathrm{AFB}_{1}$ to toxic epoxide AFBO. It should be noted that this activation was evidenced indirectly by the formation of a dihydrodiol-Tris conjugate in this study because of the instability and short half-life of the AFBO [47,48]. AFB 1 epoxide easily undergoes hydrolysis at neutral solution and transforms into $\mathrm{AFB}_{1}$ 8,9-dihydrodiol [48], which reacts with Tris to form a highly fluorescent compound [49], thus greatly elevating the sensitivity and benefiting the detection. Therefore, the activation of $\mathrm{AFB}_{1}$ can be measured by the formation of a dihydrodiol-Tris adduct [50]. Quail liver microsomes were used as a positive control as they were reported to be highly active in $\mathrm{AFB}_{1}$ epoxidation [37,51-53]. The HPLC assays showed that the $\mathrm{AFB}_{1}$ metabolite produced by quail microsomes had the same retention time as that formed during CYP3A29 reaction with $\mathrm{AFB}_{1}$, suggesting that CYP3A29 was capable of oxidizing $\mathrm{AFB}_{1}$ into $\mathrm{AFBO}$.

On the primary structure, CYP3A29 enzyme consists of 503 residues and is believed to be the homolog of human CYP3A4 because it shares 77\% sequence identity with CYP3A4. Similar to human CYP3A4, CYP3A29 has a series of key amino acid residues that contribute to effector binding and cooperativity. For example, Leu-210 and Leu-211 are believed to be highly conserved in CYP3A family and contribute to effector binding [54], and Phe-304 is deemed to play dual roles in cooperativity, regioselectivity, and stereoselectivity [55-57]. To gain insight into the regioselectivity and substrate recognition of $C Y P 3 A 29$ towards $\mathrm{AFB}_{1}$, we mutated three residues located in substrate recognition sites, S119A, F304A, and T309A. Similar to the WT, the purified mutants possessed an ordered secondary structure that was rich in $\alpha$-helix. Furthermore, in vitro reconstitution assays showed varied oxidizing activity to nifedipine in WT and mutants, suggesting that the mutants are functional in biotransformation of exogenous compounds, though these three mutations caused the deterioration of the oxidation of CYP3A29 to nifedipine to different extents. More importantly, they exhibited different metabolism to $\mathrm{AFB}_{1}$. Thr309 played an important role in orientation of $\mathrm{AFB}_{1}$, because removal of hydroxyl group of Thr309 severely impaired $\mathrm{AFB}_{1}$ epoxidation. The CYP3A29-AFB 1 binding model deduced from molecular docking revealed that two hydrogen bonds would be formed between $\mathrm{AFB}_{1}$ and the surround residues in the active center, one of which was located between 
the hydroxyl group of Tyr309 and $\mathrm{O} 6$ or $\mathrm{O} 7 \mathrm{of} \mathrm{AFB}_{1}$ (Figure 4A). This hydrogen bond seemed to be essential for the binding of $\mathrm{AFB}_{1}$ because any alternative active orientation could be obtained when $\mathrm{AFB}_{1}$ was docked into T309A (Figure $4 \mathrm{C}$, Table 2). The data may explain the reason why the replacement of Thr309 with Ala resulted in a large loss of activity. It further supported the fact that Thr309 plays a significant role in binding and orientation of $\mathrm{AFB}_{1}$ by forming a hydrogen bond with it in the active pocket.

In contrast to the docking study for human CYP3A4, in which replacement of Phe304 with Ala caused a complete loss of $\mathrm{AFB}_{1}$ oxidation [36], the pig CYP3A29 F304A mutant exhibited enhanced activity to $\mathrm{AFB}_{1}$ epoxidation. The CYP3A4-AFB 1 binding model deduced from molecular docking reveals that a strong $\pi-\pi$ interaction between Phe304 phenyl group and the aromatic ring in $\mathrm{AFB}_{1}$ plays a key role in $\mathrm{AFB}_{1}$ binding [36]. However, we could not find the $\pi-\pi$ interaction between Phe304 and $\mathrm{AFB}_{1}$ in the docking simulation of CYP3A29 (Figure $4 \mathrm{~A}$ ). Instead of the $\pi-\pi$ interaction, our CYP3A29 docking model showed the side-chain phenyl group of Phe304 is a steric hindrance and, therefore, results in energetically unfavorable binding for $\mathrm{AFB}_{1}$ (binding energy, $-8.55 \mathrm{kcal} / \mathrm{mol}$, Table 2). We believe that in the mutant F304A, removal of the bulk side-chain phenyl group of Phe304 allows the ligand $\mathrm{AFB}_{1}$ molecule to be located closer to the I-helix and allows the formation of another hydrogen bond between the hydroxyl group of Ser119 and the oxygen atom at $\mathrm{C} 1$ or $\mathrm{C} 11$ in $\mathrm{AFB}_{1}$ which additionally stabilized $\mathrm{AFB}_{1}$. This is supported by the more proportional conformations $(87 \%)$ and a lower binding energy $(-8.74 \mathrm{kcal} / \mathrm{mol}$, Table 2$)$ obtained in the molecular docking, in comparison with those of WT. These results can explain why F304A exhibited enhanced activation towards $\mathrm{AFB}_{1}$ compared to WT.

The capacity of activating $\mathrm{AFB}_{1}$ was observed to be weakened but not significantly in the S119A mutant. However, the direct interaction between Ser119 and $\mathrm{AFB}_{1}$ could not be observed in the binding model deduced by molecular docking (Figure 4A). Meanwhile, $\mathrm{AFB}_{1}$ docking into S119A did not produce substantial differences compared to the WT, neither in the conformations nor the lowest energy (Table 2). It is reported that Ser119-mediated polar interactions play an important role in CYP3A4-ligand binding regardless of the hydrogen bond [58]. It is suggested that Ser119 might potentially contribute in mediating the $\mathrm{AFB}_{1}$ binding.

It should be pointed out that the interactions of these residues with $\mathrm{AFB}_{1}$ were deduced from molecular dockings because no CYP3A29 crystal structure was available. Allowing for the high sequence identity with human CYP3A4, it is supposed that the data would more likely be compatible with the authentic 3D model of CYP3A29, which calls for further validation in future study.

Based on previous studies and this research, it can be concluded that the regioselectivity of CYP3A29 towards different substrates is complicated and relatively difficult to predict. For instance, recent research suggests that Arg105, Arg106, Ser119, and Lys212 in CYP3A29 play important roles in the hydroxylation of the T-2 toxin [35]; many of them are not addressed in our study, with the exception of Ser119, which has only a slight and uncertain effect on $\mathrm{AFB}_{1}$ epoxidation. However, for the first time we have revealed that CYP3A29 is capable to oxidize $\mathrm{AFB}_{1}$ and it possibly has a different molecular mechanism to human CYP3A4. This is an example of the diversity of $\mathrm{AFB}_{1}$ recognition and probably other exogenous substrates for the evolutionarily conserved P450 isoforms.

\section{Conclusions}

In summary, this study clearly demonstrates that CYP3A29 is capable of activating $\mathrm{AFB}_{1}$ into AFBO. To our knowledge, this is the first report about pig CYP that involves $\mathrm{AFB}_{1}$ bioactivation. In addition, Thr309 in pig CYP3A29 plays a significant role in the stabilization of $\mathrm{AFB}_{1}$ binding in the active center through a hydrogen bond. Unlike human CYP3A4, removing the bulk side chain eliminates the steric hindrance of the phenyl group to the binding of $\mathrm{AFB}_{1}$, which enhances CYP3A29 epoxidation activity towards $\mathrm{AFB}_{1}$ in mutant $\mathrm{F} 304 \mathrm{~A}$. Ser119 may mediate the binding of $\mathrm{AFB}_{1}$ by polar contact. Our study provides a reference for understanding the metabolic characteristics of $\mathrm{AFB}_{1}$ in 
pigs, which differs from well-studied CYP3A4 in human, and encourages further in vivo studies on the roles of CYP3A29.

\section{Experimental Section}

\subsection{Ethics Statement}

All the experiments involving the use of animals were conducted in accordance with the recommendations in the Regulations for the Administration of Affairs Concerning Experimental Animals of Guangdong province, China. This research was approved by Laboratory Animal Ethics Committee of South China Agricultural University, and the approval number was 2015-04. A Duroc $\times$ Yorkshire $\times$ Landrace crossbred pig (4-5 months old) and three quails were used from Animal Husbandry Institute, Guangdong Academy of Agricultural Sciences. The quail livers were isolated to make the microsomes. The animals were sacrificed by injection of excess sodium pentobarbital, and then the surgeries of liver separation were performed.

\subsection{Materials}

$\mathrm{AFB}_{1}$ was purchased from Fermentek (Jerusalem, Israel). E.Z.N.A ${ }^{\circledR}$ Total RNA Kit was purchased from Omega Bio-Tek (Norcross, GA, USA). Prime Script RT reagent kit and restriction endonucleases were obtained from Takara BIO Inc. (Kyoto, Japan). High fidelity DNA polymerase KOD-Plus- and KOD FX were from Toyobo (Osaka, Japan). QuikChange site-directed mutagenesis kit was purchased from Stratagene (La Jolla, CA, USA). Isopropyl- $\beta$-D-thiogalactoside (IPTG) and NADPH were from Gen-View Scientific Inc. (Wellington, FL, USA). Nifedipine ( $>98 \%$ purity), oxidized nifedipine ( $\sim 95 \%$ purity) standards, NADPH cytochrome P450 oxidoreductase ( $94 \%$ purity), and cytochrome $\mathrm{b}_{5}(\geq 90 \%$ purity) were purchased from Sigma-Aldrich Corporation (St. Louis, MO, USA). A 5-mL HisTrap HP column was purchased from GE Healthcare (Uppsala, Sweden). A ZORBAX SB-C 18 column $(4.6 \times 250 \mathrm{~mm}, 5 \mu \mathrm{m})$ was purchased from Agilent Technologies (Palo Alto, CA, USA). Chromatographic grade acetonitrile, methanol, and formic acid were obtained from Merck (Darmstadt, Germany). All the primers were synthesized in Invitrogen Biotechnology (Guangzhou, China). All the other reagents and chemicals used were of analytical grade available.

\subsection{Molecular Cloning of Pig CYP3A29}

Total RNA was isolated from porcine liver using a Total RNA kit. The first-strand cDNA was synthesized from $2 \mu \mathrm{g}$ of total RNA using a Prime Script RT reagent kit. According to the published mRNA sequence of pig CYP3A29 (NCBI NM_214423), the forward primer 5'-GGAAAATC CGAGGAGAGAATCA-3' ${ }^{\prime}$ and the reverse primer 5'-CATCAAAGCCCAAGTCCTTAGAG-3' were designed to amplify the interest gene. $\mathrm{PCR}$ reaction was performed using a thermocycling program that ran for $2 \mathrm{~min}$ at $94{ }^{\circ} \mathrm{C}$ and then proceeded for 32 cycles at $98^{\circ} \mathrm{C}$ for $10 \mathrm{~s}, 60^{\circ} \mathrm{C}$ for $30 \mathrm{~s}$, and $68^{\circ} \mathrm{C}$ for $1.5 \mathrm{~min}$. The PCR product was ligated into the pMD 19-T vector through TA cloning. The CYP3A29 gene sequence was verified by DNA sequencing. Subsequently, CYP3A29 gene was subcloned into the pCW Ori ${ }^{+}$expression vector. To allow functional expression in E. coli, the cDNA fragment encoding the bacterial ompA leader sequence were fused to CYP3A29 by PCR in frame with the initiation codon [59]. The leader sequence was proteolytically removed during bacterial synthesis, thus releasing the native CYP3A29. To purify efficiently the recombinant protein, $6 \times$ His tag encoding sequence were appended to the $3^{\prime}$ terminus of CYP3A29 gene. The resulting plasmid was confirmed by DNA sequencing and named $\mathrm{pCW} / 3 \mathrm{~A} 29$.

\subsection{Site-Directed Mutagenesis}

The pCW/3A29 expression vector was used as the plasmid DNA template for oligonucleotide-directed mutagenesis. According to our preliminary docking results and other related reports [36,55], the S119A, F304A, and T309A mutants were prepared using a QuikChange 
site-directed mutagenesis kit. The primers used for mutagenesis were $5^{\prime}$-CTATGAGAAACGCTCTCGC TCTGGCTGAGGATGA-3' for S119A, 5' -CCAAGGTATTATTTTTATTGCTGCTGGCTATGAGAC-3' for F304A, and 5'-TATTTTTGCTGGCTATGAGGCCACTAGCAGTGCTCT-3' for T309A. All of the mutations were verified by DNA sequencing.

\subsection{Protein Expression and Purification}

Recombinant CYP3A29 and the mutants were expressed in E. coli DH5 $\alpha$ cells. A single colony containing the recombinant plasmid was inoculated and cultured in $500 \mathrm{~mL}$ of TB broth containing $100 \mu \mathrm{g} / \mathrm{mL}$ ampicillin, $1 \mathrm{mM}$ thiamine, and a mixture of trace elements. The cells were grown at $37{ }^{\circ} \mathrm{C}$ until the absorbance at $600 \mathrm{~nm}$ reached 0.8 . Then, the expression was induced at $30{ }^{\circ} \mathrm{C}$ by the addition of $1 \mathrm{mM}$ isopropyl $\beta$-D-thiogalactoside (IPTG). After $36 \mathrm{~h}$, the cells were harvested and treated by $0.25 \mathrm{mg} / \mathrm{mL}$ of lysozyme. The techniques used for cell disruption, preparation of spheroplasts, and isolation of membranes were as described previously [60] with some modifications. The bacterial membrane fragments collected by ultracentrifugation were solubilized in ice-cold buffer A (100 mM potassium phosphate, $500 \mathrm{mM} \mathrm{KCl,} \mathrm{10 \%} \mathrm{glycerol,} 0.2 \mathrm{mM}$ dithiothreitol, $1 \mathrm{mM}$ EDTA, $20 \mathrm{mM}$ imidazole, $\mathrm{pH} 7.4$ ) containing $0.5 \%$ CHAPS and $0.65 \%$ sodium cholate. Then the suspension was centrifuged with $20,000 \mathrm{rpm}$ at $4{ }^{\circ} \mathrm{C}$ for $30 \mathrm{~min}$, and the supernatant was filtered through $0.22 \mu \mathrm{m}$ nylon membrane and loaded onto a $5 \mathrm{~mL}$ HisTrap HP column pre-equilibrated with buffer A. The recombinant protein was eluted with a linear gradient of 100 to $500 \mathrm{mM}$ imidazole in buffer $\mathrm{B}$ (100 mM potassium phosphate, $500 \mathrm{mM} \mathrm{KCl,} \mathrm{10 \%} \mathrm{glycerol,} 0.2 \mathrm{mM}$ dithiothreitol, $1 \mathrm{mM}$ EDTA, $500 \mathrm{mM}$ imidazole, $\mathrm{pH}$ 7.4). The fractions were combined and dialyzed against the buffer (100 $\mathrm{mM}$ potassium phosphate, $500 \mathrm{mM} \mathrm{KCl}, 20 \%$ glycerol, $0.2 \mathrm{mM}$ dithiothreitol, $1 \mathrm{mM}$ EDTA, pH 7.4) at $4{ }^{\circ} \mathrm{C}$ for $24 \mathrm{~h}$. Aliquots of the proteins were stored at $-80^{\circ} \mathrm{C}$.

\subsection{CO Difference Spectrum}

$\mathrm{Fe}^{2+} \cdot \mathrm{CO}$ vs. $\mathrm{Fe}^{2+}$ difference spectra of the recombinant CYP3A29 and the mutants were collected as described previously [61] on a UV-2550 spectrophotometer (SHIMADZU, Kyoto, Japan). The concentrations of cytochromes P450 were calculated from the absorption change at $450 \mathrm{~nm}$ relative to that at $490 \mathrm{~nm}$ using the extinction coefficient $\varepsilon_{450-490}=91 \mathrm{mM}^{-1} \cdot \mathrm{cm}^{-1}$ [61].

\subsection{Spectroscopy}

Far-UV CD spectra of the recombinant CYP3A29 and the mutants were collected on a Chirascan spectrometer (Applied Photophysics, Leatherhead, UK). The measurement parameters and methods employed were described as previously [62]. The contents of the secondary structure of proteins were estimated by CONTINLL algorithm [40], which gave the smallest RMSD.

\subsection{Reconstitution of Nifedipine Oxidation by CYP3A29 and the Mutants}

Reconstitution of a nifedipine-oxidized system followed the method of Shaw et al. [63] with some modifications. Briefly, the incubation mixture consisted of $0.05 \mu \mathrm{M}$ recombinant CYP protein, $0.1 \mu \mathrm{M}$ NADPH cytochrome P450 oxidoreductase, $0.1 \mu \mathrm{M}$ cytochrome $b_{5}, 0.02 \mathrm{mg} / \mathrm{mL}$ liposomes (L- $\alpha$-dilauroyl-sn-glycero-3-phosphocholine, L- $\alpha$-diloleoyl-sn-glycero-3-phosphocholine, L- $\alpha$-dilauroyl-sn-glycero-3-phosphoserine (1:1:1, $w / w / w$ per milliliter), $0.2 \mathrm{mg} / \mathrm{mL}$ sodium cholate, $3 \mathrm{mM}$ glutathione, $30 \mathrm{mM} \mathrm{MgCl}$, and $200 \mu \mathrm{M}$ nifedipine in $100 \mathrm{mM}$ potassium phosphate buffer ( $\mathrm{pH}$ 7.4), making a final volume of $200 \mu \mathrm{L}$. The reaction was initiated by the addition of $1 \mathrm{mM}$ $\mathrm{NADPH}$ (final concentration) and performed at $37^{\circ} \mathrm{C}$ for $10 \mathrm{~min}$, before being terminated by $2 \mathrm{~mL}$ of cold methylene chloride. After being added into $100 \mu \mathrm{L}$ of $2 \mathrm{M}$ sodium carbonate buffer ( $\mathrm{pH} 10.5$ ), the mixtures were centrifuged at $3000 \mathrm{~g}$ for $10 \mathrm{~min}$. The combined organic layers were transferred and evaporated to dryness under a stream of high-pure nitrogen. The residue was redissolved in $150 \mu \mathrm{L}$ of methanol and analyzed by HPLC. HPLC analyses were performed on a Waters Alliance system equipped with 2695 separation module. A symmetry reverse-phase $\mathrm{C}_{18}$ column was used to 
analyze the substrates nifedipine and their metabolites. The injection volume was $20 \mu \mathrm{L}$. An isocratic elution with $55 \%(v / v)$ methanol in water was applied to separate the substrates and the metabolites with a flow rate of $1 \mathrm{~mL} / \mathrm{min}$ at $30{ }^{\circ} \mathrm{C}$. Elution was monitored by the UV absorbance at $254 \mathrm{~nm}$. The nifedipine and oxidized nifedipine standards were used as the controls to identify the substrate and the product.

\subsection{Incubation of Recombinant CYP3A29 and the Mutants with AFB 1}

The recombinant CYP3A29 was incubated in the presence or absence of $5 \mu \mathrm{M}$ ketoconazole with $0.1 \mu \mathrm{M}$ NADPH cytochrome P450 oxidoreductase, $0.1 \mu \mathrm{M}$ cytochrome $b_{5}, 0.02 \mathrm{mg} / \mathrm{mL}$ liposomes (L- $\alpha$-dilauroyl-sn-glycero-3-phosphocholine, L- $\alpha$-diloleoyl-sn-glycero-3-phosphocholine, L- $\alpha$-dilauroyl-sn-glycero-3-phosphoserine (1:1:1, $w / w / w$ per milliliter), $0.2 \mathrm{mg} / \mathrm{mL}$ sodium cholate, $3 \mathrm{mM}$ glutathione, $30 \mathrm{mM} \mathrm{MgCl} 2,50 \mathrm{mM}$ Tris, and $8 \mu \mathrm{M} \mathrm{AFB}{ }_{1}$ in $100 \mathrm{mM}$ potassium phosphate buffer (pH 7.4). Subsequently, the mutants S119A, F304A and T309A were incubated in the reconstitution system without ketoconazole. The reaction was initiated by the addition of $1 \mathrm{mM}$ NADPH (final concentration) and performed at $37^{\circ} \mathrm{C}$ for $3 \mathrm{~h}$ prior to termination by addition of $200 \mu \mathrm{L}$ ice-cold methanol spiked with $0.76 \mu \mathrm{M}$ aflatoxin $\mathrm{G}_{1}$ as an internal standard. The samples were kept at $-20{ }^{\circ} \mathrm{C}$ overnight to facilitate protein precipitation and then centrifuged at $10,000 \mathrm{~g}$ for 15 min prior to analysis $[22,64]$. The supernatants were filtered through a $0.2 \mu \mathrm{m}$ nylon membrane before being injected into the HPLC. AFB $_{1}-8,9$-dihydrodiol generated in this incubation system reacted with Tris to form a highly fluorescent compound [49]. Quail liver microsomes were made and used as a positive control to determine the peak retention time of the dihydrodiol-Tris conjugate [37,38]. The major metabolite was identified by LC/MS.

\subsection{Detection of $A F B_{1}$ Metabolites by HPLC}

The $\mathrm{AFB}_{1}$ metabolites produced by CYP3A29 and the mutants were detected on a Waters Alliance e2695 liquid chromatography system (Waters Corporation, Milford, MA, USA) equipped with a 2475 fluorescence detector. Samples were separated at $25^{\circ} \mathrm{C}$ on a ZORBAX SB-C 18 column. The mobile phase, the gradient schedule, and detection condition were described as previously [62]. The flow rate was set to $1 \mathrm{~mL} / \mathrm{min}$, and the injection volume was $40 \mu \mathrm{L}$.

\subsection{Homology Modeling and Molecular Docking}

Because of the high sequence identity of CYP3A29 with human CYP3A4 (77\%), the three-dimensional structure model of CYP3A29 was built using SWISS-MODEL server as a homology modeling tool [65-67], based on the X-ray crustal structure of human CYP3A4 [68]. To retain the reliability of the model, the hydrophobic $\mathrm{NH}_{2}$-terminal region of CYP3A29 (residues 3 to 24) was deleted. The quality of the resultant model structure was analyzed and evaluated by PROCHECK, What_check, Verify_3D, Errat, and Prove software (The Structure Analysis and Verification Server, Version 4, University of California, Los Angeles, LA, 2012).

A molecular docking study was conducted to construct a binding model of AFB $_{1}$ to CYP3A29. The AutoDock 4.2 docking program was used to find the best configurations for receptor and ligand complex [69]. For each simulation, CYP3A29 receptor was kept rigid, while AFB $_{1}$ ligand was flexible, in which only one bond was rotatable. To cover the whole active site of CYP3A29, the grid box was set to $60 \times 60 \times 60$ points with spacing of $0.375 \AA$. The box center was set at $60.055,76.691$, and 9.028. AutoDockTools 1.5.6 (The Scripps Research Institute, La Jolla, CA, USA) was used to add Gasteiger charges to the CYP3A29 coordinates and AFB 1 . The Lamarckian genetic algorithm was used to determine the globally optimized conformations and orientations of the ligand with minimized free energy. All the docking simulations were performed with 100 cycles of running using an initial population size of 150 and a maximum of 2.5 million energy evaluations. The other parameters were set at their default values. Docking results were clustered using a root mean square deviation (RMSD) of $2.0 \AA$ and were ranked according to the change in free energy $(\Delta G)$ estimated by AutoDock. 
Conformations with the lowest free energies of binding were selected as the best binding modes. Molecular graphics were generated by PyMOL [42].

\subsection{Statistical Analysis}

Resulting data are reported as the mean and standard error of means (Mean $\pm \mathrm{SE}$ ) based on at least three independent experiments. Statistical significance of differences between means was assessed by two-tailed $t$ test and $p<0.05$ was considered significant.

Supplementary Materials: The following are available online at www.mdpi.com/2072-6651/8/9/267/s1, Figure S1: The identification of metabolite by LC-MS/MS; Figure S2: The side view of docking model; Table S1: The relative quantification of metabolic activities of CYP3A29 and its mutants to $\mathrm{AFB}_{1}$.

Acknowledgments: The authors thank Ruoxu Gu, Shanghai Jiao Tong University, for his help in molecular docking, and Guangdong Test Center for Green Labeling, for technical assistance with LC-MS/MS. This work was supported by the Natural Science Foundation of Guangdong Province, China (2015A030312005) and the Program for Changjiang Scholars and Innovative Research Team in University (No. IRT13063).

Author Contributions: Jun Wu, Yiqun Deng, and Jikai Wen conceived and designed the experiments; Jun $\mathrm{Wu}$, Ruohong Chen, Caihui Zhang, Kangbai Li, and Weiying Xu performed the experiments; Peiqiang Mu and Jun Jiang analyzed the data; Ruohong Chen, Lijuan Wang, and Qingmei Chen contributed reagents/materials/analytic tools; Jun $\mathrm{Wu}$, Jikai Wen, and Yiqun Deng wrote the paper.

Conflicts of Interest: The authors declare no conflict of interest.

\section{Abbreviations}

The following abbreviations are used in this manuscript:

$\begin{array}{ll}\text { AFB }_{1} & \text { aflatoxin } B_{1} \\ \text { CYP } & \text { Cytochrome P450 } \\ \text { AFG } & \text { aflatoxin } G_{1} \\ \text { AFBO } & \text { AFB }_{1} \text { exo-8,9-epoxide } \\ \text { WT } & \text { wide-type } \\ \text { IPTG } & \text { isopropyl- } \beta \text {-D-thiogalactoside } \\ \text { CHAPS } & \text { 3-[(3-cholamidopropyl)dimethylammonio]-1-propanesulfonate } \\ \text { EDTA } & \text { ethylenediaminetetraacetic acid } \\ \text { NADPH } & \text { nicotinamide adenine dinucleotide phosphate } \\ \text { NCBI } & \text { National Center for Biotechnology Information } \\ \text { HPLC } & \text { High-performance liquid chromatography } \\ \text { CD } & \text { circular dichroism } \\ \text { RMSD } & \text { root mean square deviation } \\ \text { BHA } & \text { butylated hydroxyanisole }\end{array}$

\section{References}

1. Roebuck, B.D. Hyperplasia, partial hepatectomy, and the carcinogenicity of aflatoxin B1. J. Cell. Biochem. 2004, 91, 243-249. [CrossRef] [PubMed]

2. Li, L.; Wang, H. Heterogeneity of liver cancer and personalized therapy. Cancer Lett. 2016, 379, 191-197. [CrossRef] [PubMed]

3. Dohnal, V.; Wu, Q.; Kuca, K. Metabolism of aflatoxins: Key enzymes and interindividual as well as interspecies differences. Arch. Toxicol. 2014, 88, 1635-1644. [CrossRef] [PubMed]

4. Roze, L.V.; Hong, S.Y.; Linz, J.E. Aflatoxin biosynthesis: Current frontiers. Annu. Rev. Food Sci. Technol. 2013, 4, 293-311. [CrossRef] [PubMed]

5. Baertschi, S.W.; Raney, K.D.; Shimada, T.; Harris, T.M.; Guengerich, F.P. Comparison of rates of enzymatic oxidation of aflatoxin B1, aflatoxin G1, and sterigmatocystin and activities of the epoxides in forming guanyl-N7 adducts and inducing different genetic responses. Chem. Res. Toxicol. 1989, 2, 114-122. [CrossRef] [PubMed]

6. $\quad$ Essigmann, J.M.; Croy, R.G.; Nadzan, A.M.; Busby, W.F., Jr.; Reinhold, V.N.; Buchi, G.; Wogan, G.N. Structural identification of the major DNA adduct formed by aflatoxin b1 in vitro. Proc. Natl. Acad. Sci. USA 1977, 74, 1870-1874. [CrossRef] [PubMed] 
7. Choy, W.N. A review of the dose-response induction of DNA adducts by aflatoxin B1 and its implications to quantitative cancer-risk assessment. Mutat. Res. 1993, 296, 181-198. [CrossRef]

8. Crespi, C.L.; Penman, B.W.; Steimel, D.T.; Gelboin, H.V.; Gonzalez, F.J. The development of a human cell line stably expressing human CYP3A4: Role in the metabolic activation of aflatoxin B1 and comparison to CYP1A2 and CYP2A3. Carcinogenesis 1991, 12, 355-359. [CrossRef] [PubMed]

9. Aoyama, T.; Yamano, S.; Guzelian, P.S.; Gelboin, H.V.; Gonzalez, F.J. Five of 12 forms of vaccinia virus-expressed human hepatic cytochrome P450 metabolically activate aflatoxin B1. Proc. Natl. Acad. Sci. USA 1990, 87, 4790-4793. [CrossRef] [PubMed]

10. Shimada, T.; Guengerich, F.P. Evidence for cytochrome P-450NF, the nifedipine oxidase, being the principal enzyme involved in the bioactivation of aflatoxins in human liver. Proc. Natl. Acad. Sci. USA 1989, 86, 462-465. [CrossRef] [PubMed]

11. Gallagher, E.P.; Kunze, K.L.; Stapleton, P.L.; Eaton, D.L. The kinetics of aflatoxin b1 oxidation by human cDNA-expressed and human liver microsomal cytochromes P450 1A2 and 3A4. Toxicol. Appl. Pharmacol. 1996, 141, 595-606. [CrossRef] [PubMed]

12. Gallagher, E.P.; Wienkers, L.C.; Stapleton, P.L.; Kunze, K.L.; Eaton, D.L. Role of human microsomal and human complementary DNA-expressed cytochromes P4501A2 and P4503A4 in the bioactivation of aflatoxin b1. Cancer Res. 1994, 54, 101-108. [PubMed]

13. Ramsdell, H.S.; Eaton, D.L. Species susceptibility to aflatoxin B1 carcinogenesis: Comparative kinetics of microsomal biotransformation. Cancer Res. 1990, 50, 615-620. [PubMed]

14. Guengerich, F.P.; Turvy, C.G. Comparison of levels of several human microsomal cytochrome P-450 enzymes and epoxide hydrolase in normal and disease states using immunochemical analysis of surgical liver samples. J. Pharmacol. Exp. Ther. 1991, 256, 1189-1194. [PubMed]

15. Ueng, Y.F.; Shimada, T.; Yamazaki, H.; Guengerich, F.P. Oxidation of aflatoxin B1 by bacterial recombinant human cytochrome P450 enzymes. Chem. Res. Toxicol. 1995, 8, 218-225. [CrossRef] [PubMed]

16. Iyer, R.S.; Coles, B.F.; Raney, K.D.; Thier, R.; Guengerich, F.P.; Harris, T.M. DNA adduction by the potent carcinogen aflatoxin B1: Mechanistic studies. J. Am. Chem. Soc. 1994, 116, 1603-1609. [CrossRef]

17. Raney, K.D.; Coles, B.; Guengerich, F.P.; Harris, T.M. The endo-8,9-epoxide of aflatoxin B1: A new metabolite. Chem. Res. Toxicol. 1992, 5, 333-335. [CrossRef] [PubMed]

18. Towles, J.K.; Clark, R.N.; Wahlin, M.D.; Uttamsingh, V.; Rettie, A.E.; Hardy Jackson, K. Cytochrome P450 3A4 and CYP3A5-catalyzed bioactivation of lapatinib. Drug Metab. Dispos. 2016, 44, 1584-1597. [CrossRef] [PubMed]

19. Nookala, A.R.; Li, J.; Ande, A.; Wang, L.; Vaidya, N.K.; Li, W.; Kumar, S.; Kumar, A. Effect of methamphetamine on spectral binding, ligand docking and metabolism of anti-hiv drugs with CYP3A4. PLoS ONE 2016, 11, e0146529. [CrossRef] [PubMed]

20. Hong, Y.; Chia, Y.M.; Yeo, R.H.; Venkatesan, G.; Koh, S.K.; Chai, C.L.; Zhou, L.; Kojodjojo, P.; Chan, E.C. Inactivation of human cytochrome P450 3A4 and 3A5 by dronedarone and N-desbutyl dronedarone. Mol. Pharmacol. 2016, 89, 1-13. [CrossRef] [PubMed]

21. Sevrioukova, I.F.; Poulos, T.L. Current approaches for investigating and predicting cytochrome P450 3A4-ligand interactions. Adv. Exp. Med. Biol. 2015, 851, 83-105. [PubMed]

22. Rawal, S.; Coulombe, R.A., Jr. Metabolism of aflatoxin B1 in turkey liver microsomes: The relative roles of cytochromes P450 1A5 and 3A37. Toxicol. Appl. Pharmacol. 2011, 254, 349-354. [CrossRef] [PubMed]

23. Guerre, P.; Pineau, T.; Costet, P.; Burgat, V.; Galtier, P. Effects of AFB1 on CYP 1A1, 1A2 and 3A6 mRNA, and P450 expression in primary culture of rabbit hepatocytes. Toxicol. Lett. 2000, 111, 243-251. [CrossRef]

24. Kelly, J.D.; Eaton, D.L.; Guengerich, F.P.; Coulombe, R.A., Jr. Aflatoxin B1 activation in human lung. Toxicol. Appl. Pharmacol. 1997, 144, 88-95. [CrossRef] [PubMed]

25. Crespi, C.L.; Penman, B.W.; Leakey, J.A.; Arlotto, M.P.; Stark, A.; Parkinson, A.; Turner, T.; Steimel, D.T.; Rudo, K.; Davies, R.L.; et al. Human cytochrome P450IIA3: Cdna sequence, role of the enzyme in the metabolic activation of promutagens, comparison to nitrosamine activation by human cytochrome P450IIE1. Carcinogenesis 1990, 11, 1293-1300. [CrossRef] [PubMed]

26. Zhang, Z.; Lu, H.; Huan, F.; Meghan, C.; Yang, X.; Wang, Y.; Wang, X.; Wang, X.; Wang, S.L. Cytochrome P450 2A13 mediates the neoplastic transformation of human bronchial epithelial cells at a low concentration of aflatoxin B1. Int. J. Cancer 2014, 134, 1539-1548. [CrossRef] [PubMed] 
27. Yang, X.; Zhang, Z.; Wang, X.; Wang, Y.; Zhang, X.; Lu, H.; Wang, S.L. Cytochrome P450 2 A13 enhances the sensitivity of human bronchial epithelial cells to aflatoxin B1-induced DNA damage. Toxicol. Appl. Pharmacol. 2013, 270, 114-121. [CrossRef] [PubMed]

28. Shimada, T.; Yamazaki, H.; Mimura, M.; Inui, Y.; Guengerich, F.P. Interindividual variations in human liver cytochrome P-450 enzymes involved in the oxidation of drugs, carcinogens and toxic chemicals: Studies with liver microsomes of 30 japanese and 30 caucasians. J. Pharmacol. Exp. Ther. 1994, 270, 414-423. [PubMed]

29. Gillam, E.M.; Guo, Z.; Ueng, Y.F.; Yamazaki, H.; Cock, I.; Reilly, P.E.; Hooper, W.D.; Guengerich, F.P. Expression of cytochrome P450 3A5 in escherichia coli: Effects of $5^{\prime}$ modification, purification, spectral characterization, reconstitution conditions, and catalytic activities. Arch. Biochem. Biophys. 1995, 317, 374-384. [CrossRef] [PubMed]

30. Kamdem, L.K.; Meineke, I.; Godtel-Armbrust, U.; Brockmoller, J.; Wojnowski, L. Dominant contribution of P450 3A4 to the hepatic carcinogenic activation of aflatoxin B1. Chem. Res. Toxicol. 2006, 19, 577-586. [CrossRef] [PubMed]

31. Wang, H.; Dick, R.; Yin, H.; Licad-Coles, E.; Kroetz, D.L.; Szklarz, G.; Harlow, G.; Halpert, J.R.; Correia, M.A. Structure-function relationships of human liver cytochromes P450 3A: Aflatoxin B1 metabolism as a probe. Biochemistry 1998, 37, 12536-12545. [CrossRef] [PubMed]

32. Donato, M.T.; Castell, J.V.; Gomez-Lechon, M.J. Characterization of drug metabolizing activities in pig hepatocytes for use in bioartificial liver devices: Comparison with other hepatic cellular models. J. Hepatol. 1999, 31, 542-549. [CrossRef]

33. Meissonnier, G.M.; Laffitte, J.; Loiseau, N.; Benoit, E.; Raymond, I.; Pinton, P.; Cossalter, A.M.; Bertin, G.; Oswald, I.P.; Galtier, P. Selective impairment of drug-metabolizing enzymes in pig liver during subchronic dietary exposure to aflatoxin B1. Food Chem. Toxicol. 2007, 45, 2145-2154. [CrossRef] [PubMed]

34. Yao, M.; Dai, M.; Liu, Z.; Huang, L.; Chen, D.; Wang, Y.; Peng, D.; Wang, X.; Liu, Z.; Yuan, Z. Comparison of the substrate kinetics of pig CYP3A29 with pig liver microsomes and human CYP3A4. Biosci. Rep. 2011, 31, 211-220. [CrossRef] [PubMed]

35. Cheng, G.; Liu, C.; Wang, X.; Ma, H.; Pan, Y.; Huang, L.; Hao, H.; Dai, M.; Yuan, Z. Structure-function analysis of porcine cytochrome P450 3A29 in the hydroxylation of T-2 toxin as revealed by docking and mutagenesis studies. PLoS ONE 2014, 9, e106769. [CrossRef] [PubMed]

36. Xue, L.; Wang, H.F.; Wang, Q.; Szklarz, G.D.; Domanski, T.L.; Halpert, J.R.; Correia, M.A. Influence of p450 3A4 SRS-2 residues on cooperativity and/or regioselectivity of aflatoxin $\mathrm{B}(1)$ oxidation. Chem. Res. Toxicol. 2001, 14, 483-491. [CrossRef] [PubMed]

37. Hayes, J.D.; Judah, D.J.; McLellan, L.I.; Kerr, L.A.; Peacock, S.D.; Neal, G.E. Ethoxyquin-induced resistance to aflatoxin $\mathrm{B} 1$ in the rat is associated with the expression of a novel alpha-class glutathione S-transferase subunit, Yc2, which possesses high catalytic activity for aflatoxin B1-8,9-epoxide. Biochem. J. 1991, 279, 385-398. [CrossRef] [PubMed]

38. Moss, E.J.; Judah, D.J.; Przybylski, M.; Neal, G.E. Some mass-spectral and n.M.R. Analytical studies of a glutathione conjugate of aflatoxin B1. Biochem. J. 1983, 210, 227-233. [CrossRef] [PubMed]

39. Neal, G.E.; Judah, D.J.; Green, J.A. The in vitro metabolism of aflatoxin B1 catalyzed by hepatic microsomes isolated from control or 3-methylcholanthrene-stimulated rats and quail. Toxicol. Appl. Pharmacol. 1986, 82, 454-460. [CrossRef]

40. Sreerama, N.; Woody, R.W. Estimation of protein secondary structure from circular dichroism spectra: Comparison of CONTIN, SELCON, and CDSSTR methods with an expanded reference set. Anal. Biochem. 2000, 287, 252-260. [CrossRef] [PubMed]

41. Laskowski, R.A.; Rullmannn, J.A.; MacArthur, M.W.; Kaptein, R.; Thornton, J.M. AQUA and PROCHECK-NMR: Programs for checking the quality of protein structures solved by NMR. J. Biomol. NMR 1996, 8, 477-486. [CrossRef] [PubMed]

42. The Pymol Molecular Graphics System, version 1.8. Schrodinger, LLC: New York, NY, USA, 2015.

43. Diaz, G.J.; Murcia, H.W.; Cepeda, S.M.; Boermans, H.J. The role of selected cytochrome P450 enzymes on the bioactivation of aflatoxin B1 by duck liver microsomes. Avian Pathol. 2010, 39, 279-285. [CrossRef] [PubMed]

44. Ge, X.H.; Wang, J.P.; Liu, J.; Jiang, J.; Lin, H.N.; Wu, J.; Ouyang, M.; Tang, X.Q.; Zheng, M.; Liao, M.; et al. The catalytic activity of cytochrome P450 3A22 is critical for the metabolism of T-2 toxin in porcine reservoirs. Catal. Commun. 2010, 12, 71-75. [CrossRef] 
45. Liu, J.; Ge, X.H.; Man, O.Y.; Tang, X.Q.; Wu, J.; Wang, J.P.; Jiang, J.; Huen, M.S.Y.; Deng, Y.Q. Catalytic characteristics of CYP3A22-dependent mequindox detoxification. Catal. Commun. 2011, 12, 637-643. [CrossRef]

46. Wang, J.; Jiang, J.; Zhang, H.; Wang, J.; Cai, H.; Li, C.; Li, K.; Liu, J.; Guo, X.; Zou, G.; et al. Integrated transcriptional and proteomic analysis with in vitro biochemical assay reveal the important role of CYP3A46 in T-2 toxin hydroxylation in porcine primary hepatocytes. Mol. Cell. Proteom. 2011, 10, M111.008748. [CrossRef] [PubMed]

47. Johnson, W.W.; Guengerich, F.P. Reaction of aflatoxin B1 exo-8,9-epoxide with DNA: Kinetic analysis of covalent binding and DNA-induced hydrolysis. Proc. Natl. Acad. Sci. USA 1997, 94, 6121-6125. [CrossRef] [PubMed]

48. Johnson, W.W.; Harris, T.M.; Guengerich, F.P. Kinetics and mechanism of hydrolysis of aflatoxin B1 exo-8,9-epoxide and rearrangement of the dihydrodiol. J. Am. Chem. Soc. 1996, 118, 8213-8220. [CrossRef]

49. Forrester, L.M.; Neal, G.E.; Judah, D.J.; Glancey, M.J.; Wolf, C.R. Evidence for involvement of multiple forms of cytochrome P-450 in aflatoxin b1 metabolism in human liver. Proc. Natl. Acad. Sci. USA 1990, 87, 8306-8310. [CrossRef] [PubMed]

50. Eaton, D.L.; Gallagher, E.P. Mechanisms of aflatoxin carcinogenesis. Annu. Rev. Pharmacol. Toxicol. 1994, 34, 135-172. [CrossRef] [PubMed]

51. McDonagh, P.D.; Judah, D.J.; Hayes, J.D.; Lian, L.Y.; Neal, G.E.; Wolf, C.R.; Roberts, G.C. Determinants of specificity for aflatoxin B1-8,9-epoxide in alpha-class glutathione S-transferases. Biochem. J. 1999, 339, 95-101. [CrossRef] [PubMed]

52. Ireland, L.S.; Harrison, D.J.; Neal, G.E.; Hayes, J.D. Molecular cloning, expression and catalytic activity of a human AKR7 member of the aldo-keto reductase superfamily: Evidence that the major 2-carboxybenzaldehyde reductase from human liver is a homologue of rat aflatoxin B1-aldehyde reductase. Biochem. J. 1998, 332, 21-34. [CrossRef] [PubMed]

53. Judah, D.J.; Hayes, J.D.; Yang, J.C.; Lian, L.Y.; Roberts, G.C.; Farmer, P.B.; Lamb, J.H.; Neal, G.E. A novel aldehyde reductase with activity towards a metabolite of aflatoxin B1 is expressed in rat liver during carcinogenesis and following the administration of an anti-oxidant. Biochem. J. 1993, 292, 13-18. [CrossRef] [PubMed]

54. Harlow, G.R.; Halpert, J.R. Alanine-scanning mutagenesis of a putative substrate recognition site in human cytochrome P450 3A4. Role of residues 210 and 211 in flavonoid activation and substrate specificity. J. Biol. Chem. 1997, 272, 5396-5402. [CrossRef] [PubMed]

55. Khan, K.K.; He, Y.Q.; Domanski, T.L.; Halpert, J.R. Midazolam oxidation by cytochrome P450 3A4 and active-site mutants: An evaluation of multiple binding sites and of the metabolic pathway that leads to enzyme inactivation. Mol. Pharmacol. 2002, 61, 495-506. [CrossRef] [PubMed]

56. Stevens, J.C.; Domanski, T.L.; Harlow, G.R.; White, R.B.; Orton, E.; Halpert, J.R. Use of the steroid derivative RPR 106541 in combination with site-directed mutagenesis for enhanced cytochrome P-450 3A4 structure/function analysis. J. Pharmacol. Exp. Ther. 1999, 290, 594-602. [PubMed]

57. Domanski, T.L.; Liu, J.; Harlow, G.R.; Halpert, J.R. Analysis of four residues within substrate recognition site 4 of human cytochrome P450 3A4: Role in steroid hydroxylase activity and alpha-naphthoflavone stimulation. Arch. Biochem. Biophys. 1998, 350, 223-232. [CrossRef] [PubMed]

58. Sevrioukova, I.F.; Poulos, T.L. Dissecting cytochrome P450 3A4-ligand interactions using ritonavir analogues. Biochemistry 2013, 52, 4474-4481. [CrossRef] [PubMed]

59. Pritchard, M.P.; Ossetian, R.; Li, D.N.; Henderson, C.J.; Burchell, B.; Wolf, C.R.; Friedberg, T. A general strategy for the expression of recombinant human cytochrome P450s in Escherichia coli using bacterial signal peptides: Expression of CYP3A4, CYP2A6, and CYP2E1. Arch. Biochem. Biophys. 1997, 345, 342-354. [CrossRef] [PubMed]

60. Pritchard, M.P.; McLaughlin, L.; Friedberg, T. Establishment of functional human cytochrome p450 monooxygenase systems in escherichia coli. Methods Mol. Biol. 2006, 320, 19-29. [PubMed]

61. Omura, T.; Sato, R. The carbon monoxide-binding pigment of liver microsomes. I. Evidence for its hemoprotein nature. J. Biol. Chem. 1964, 239, 2370-2378. [PubMed]

62. Wu, J.; Xu, W.; Zhang, C.; Chang, Q.; Tang, X.; Li, K.; Deng, Y. Trp266 determines the binding specificity of a porcine aflatoxin $\mathrm{B}(1)$ aldehyde reductase for aflatoxin $\mathrm{B}(1)$-dialdehyde. Biochem. Pharmacol. 2013, 86, 1357-1365. [CrossRef] [PubMed] 
63. Shaw, P.M.; Hosea, N.A.; Thompson, D.V.; Lenius, J.M.; Guengerich, F.P. Reconstitution premixes for assays using purified recombinant human cytochrome P450, nadph-cytochrome P450 reductase, and cytochrome B5. Arch. Biochem. Biophys. 1997, 348, 107-115. [CrossRef] [PubMed]

64. Klein, P.J.; Buckner, R.; Kelly, J.; Coulombe, R.A., Jr. Biochemical basis for the extreme sensitivity of turkeys to aflatoxin B(1). Toxicol. Appl. Pharmacol. 2000, 165, 45-52. [CrossRef] [PubMed]

65. Arnold, K.; Bordoli, L.; Kopp, J.; Schwede, T. The swiss-model workspace: A web-based environment for protein structure homology modelling. Bioinformatics 2006, 22, 195-201. [CrossRef] [PubMed]

66. Schwede, T.; Kopp, J.; Guex, N.; Peitsch, M.C. Swiss-model: An automated protein homology-modeling server. Nucleic Acids Res. 2003, 31, 3381-3385. [CrossRef] [PubMed]

67. Guex, N.; Peitsch, M.C. Swiss-model and the swiss-pdbviewer: An environment for comparative protein modeling. Electrophoresis 1997, 18, 2714-2723. [CrossRef] [PubMed]

68. Williams, P.A.; Cosme, J.; Vinkovic, D.M.; Ward, A.; Angove, H.C.; Day, P.J.; Vonrhein, C.; Tickle, I.J.; Jhoti, H. Crystal structures of human cytochrome P450 3A4 bound to metyrapone and progesterone. Science 2004, 305, 683-686. [CrossRef] [PubMed]

69. Morris, G.M.; Huey, R.; Lindstrom, W.; Sanner, M.F.; Belew, R.K.; Goodsell, D.S.; Olson, A.J. AutoDock4 and AutoDockTools4: Automated docking with selective receptor flexibility. J. Comput. Chem. 2009, 30, 2785-2791. [CrossRef] [PubMed]

(C) 2016 by the authors; licensee MDPI, Basel, Switzerland. This article is an open access article distributed under the terms and conditions of the Creative Commons Attribution (CC-BY) license (http:/ / creativecommons.org/licenses/by/4.0/). 